\title{
Research on Dynamic Simulation of DP for a deep Water Semi-submersible Platform
}

\author{
LIU Wei \\ State Key Lab of Autonomous Underwater Vehicle \\ Harbin Engineering University Harbin, China, \\ 15846588561, kaka19880921@126.com
}

\begin{abstract}
In the present paper a deepwater semi-submersible drilling platform is taken as the research object. The capability analysis of DP system is studied. Based on API and MARINE the external environment loads on the platform are calculated and researched. The model of dynamic positioning motion is created .The model is 6 degrees of freedom and includes a Kalman filter and PID controller. The program has been simulated to calculate the DP capability in time history for the platform under operational condition. The results of simulations proved that the DP system works well.
\end{abstract}

Keywords-semi-submersible platform; dynamic positioning; PID controller; Kalman filter; time history simulation

\section{INTRODUCTION}

As the development and utilization of offshore oil and gas resources is developing into deeper waters and more harsh environment, the traditional multi-point mooring positioning due to increase in the weight of anchor chain and the reduction of the variable load of platform deck, has been unable to meet the deep waters of positioning requirements. Modern dynamic positioning technology can not only solve the traditional economic cost, installation techniques, and water depth of a range of problems, but also has the advantages of high positioning accuracy, fast response, structural safety, powerful mobility and other advantages. Therefore, relying on its own power positioning will gradually become the mainly positioning means of various offshore floating production facilities in deepwater operations as in [1-2].

Dynamic positioning system is a closed-loop control system as in [3], which equipped with computer control system is to achieve the automatic positioning of the platform and keep the heading actually. The basic principle is to use some kind of sensor component to detect the horizontal drift and azimuth deviation for ships and floating offshore structures under the action of the external disturbance force timely, and then, based on the external environment to calculate the desired force and moment which can make the vessel or other floating offshore structures restored to the target location. Finally, the system issue commands to make thruster generate the corresponding thrust, so as to keep the vessel or platform to correct the offset state and locate within the scope of the required accuracy.

The present paper starts with the description of semiplatform and the external environment load. Next, the model of

\author{
Pang Yong-jie \\ State Key Lab of Autonomous Underwater Vehicle \\ Harbin Engineering University \\ Harbin, China
}

the external environment will be created and calculated. On the condition of wind, wave and current loads in 45 degree direction, the dynamic simulation of platform will be discussed.

\section{CAlCUlation MODEL}

The paper selected for a maximum operating depth of $3000 \mathrm{~m}$, the maximum drilling depth of $10,000 \mathrm{~m}$ deep-water semi-submersible drilling platform. The platform is the sixth generation of international drilling platform, which is equipped with a semi-derrick, and DPS-3 dynamic positioning. Eight thrusters are chose for the Dynamic positioning system which is symmetric installed at the bottom of the semi-submersible platform.

\section{A. Platform Parameters and Coordinate System}

The main components of platform include: two floating body, two cylindrical connecting elements, four columns, the main deck, the deck of the box, living cabin floor, derrick, derrick, crane, helicopter platform. The parameter of platform is shown as Table I. The reference coordinate system and environmental orientation angle are defined as in Fig. 1 .

TABLE I. PARAMETERS OF PLATFORM

\begin{tabular}{|c|c|c|c|}
\hline Parameter name & Value & Parameter name & Value \\
\hline total length & 114.07 & column length & 17.385 \\
\hline total width & 84.00 & $\begin{array}{l}\text { column width(junction } \\
\text { with the upper structure) }\end{array}$ & 15.86 \\
\hline box deck length & 77.47 & column width(middle) & 17.385 \\
\hline box deck width & 74.42 & column width(bottom) & 15.86 \\
\hline box deck height & 30 & column height & 21.46 \\
\hline upper deck height & 38.6 & column fillet radius & 3.96 \\
\hline floating body length & 114.07 & $\begin{array}{l}\text { vertical spacing of } \\
\text { column center }\end{array}$ & 58.56 \\
\hline floating body width & 20.12 & $\begin{array}{l}\text { transverse spacing of } \\
\text { column center }\end{array}$ & 58.56 \\
\hline floating body height & 8.548 & $\begin{array}{l}\text { Width between the } \\
\text { double floating-body }\end{array}$ & 78 \\
\hline
\end{tabular}




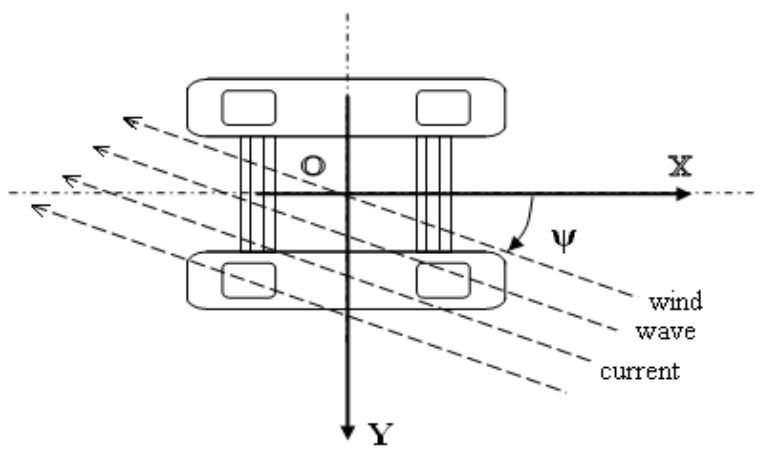

Figure 1. The reference coordinate system for the environment.

\section{ENVIROMENT LOADS}

The main work area of the deep-water semi-submersible platform is the South China Sea, as a drilling platform, may also operate in other waters, such as the deep waters of Southeast Asia, West Africa and other deep-water operations. Involved in the calculation of sea conditions are generally selected the most disadvantaged situation for dynamic positioning system of platform, namely wind, wave and current in the same direction, which considered as an approximate load for platform

Operational condition refers to the drilling or other operating condition, standby conditions is a dynamic positioning system of extreme sea conditions. In this paper, we concentrate on the drilling conditions corresponding to the sea environmental conditions shown in Table 2.

\section{A. Wind Loads}

The method is based on a component building block approach with special attention paid to component interaction and lift force effects. This means that the geometry is divided in a number of standard components with known force characteristics. In this way, steady wind loads on semisubmersibles with arbitrary geometries can be obtained. A component bounded effective wind speed $V_{a}$ is defined:

$$
V_{a}^{2}=\frac{1}{A} \iint V^{2}(y, z) d y d z
$$

Where $\mathrm{A}$ is the effective wind area and $V(\mathrm{y}, z)$ is the local

TABLE II. SEA ENVIRONMENTAL CONDITIONS

\begin{tabular}{|c|c|c|}
\hline Environment & Item & operational condition \\
\hline \multirow{4}{*}{ wave } & spectrum name & ISSC \\
\cline { 2 - 3 } & significant wave height & 6 \\
\cline { 2 - 3 } & spectral peak period & 11.2 \\
\cline { 2 - 3 } & characteristic period & 9.5 \\
\hline \multirow{2}{*}{ wind } & wind velocity & 23.2 \\
\hline current & velocity of flow & 0.93 \\
\hline
\end{tabular}

vector for the mean $\mathrm{X}$ position of the component.

The force of part I of the component is determined according to:

$$
F_{i}=\frac{1}{2} \rho_{a} V_{a}^{2} A C_{i}
$$

Where $\rho_{a}$ is the air density, $C_{i}$ is the load factor which is a function of wind direction and platform position state.

The total load of the structure is:

$$
X_{w}=\sum_{i} C_{q i} F_{i}
$$

Where $C_{q i}$ is the correction factor, the impact of wind farms, and impact among the components are taken into account.

MARIN Institute in the Netherlands have made a lot of tests to research the interaction between a variety of typical components and the preparation of the module calculates a set of semi-empirical method based on test results as in [4]and [5].The result of wind load based on the method of MARINE is shown as Fig.2.

\section{B. Current Loads}

The method of calculating the current load is the same as the wind load . For the semi-submersible platform, reference may be recommended in the API specification formula to calculate the current load. Current load will be calculated by the modular approach and in the case of drawing a flow in operational condition into a curve as shown in Fig. 3.

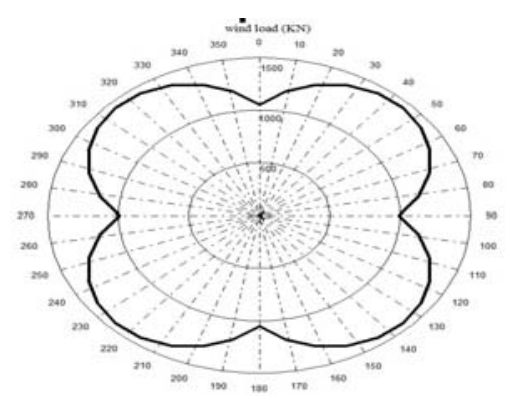

Figure 2. Wind load in operational condition

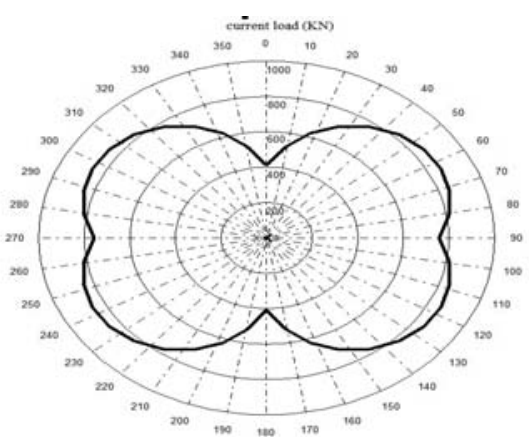

Figure 3. Current load in operational condition 


\section{Wave Forces}

Besides first-order wave force, there will also appear for long period of large amplitude slow drift movement of the force called the second-order wave drift force for the platform as in [6]. The second-order wave force is calculated based on near-field theory of Pinkster in this paper.

Application of Fourier transform, we can get second impulse response function as follows:

$$
g_{i}\left(\tau_{1}, \tau_{2}\right)=\left(\frac{1}{2 \pi}\right)^{2} \int_{-\infty}^{+\infty} \int_{-\infty}^{+\infty} G_{i}^{(2)}\left(\omega_{1}, \omega_{2}\right) e^{\left(i \omega_{1} \tau_{1}-i \omega_{2} \tau_{2}\right)} d \omega_{1} \omega_{2}
$$$$
G_{i}^{(2)}\left(\omega_{1}, \omega_{2}\right)=P\left(\omega_{1}, \omega_{2}\right)+i Q\left(\omega_{1}, \omega_{2}\right)
$$

Where $P\left(\omega_{1}, \omega_{2}\right), Q\left(\omega_{1}, \omega_{2}\right)$ is the second-order transfer function got from frequency domain, $\tau_{1}, \tau_{2}$ is the interval.

When the time history $\zeta(t)$ of wave is given, the time history of second-order wave force can be calculated.

$$
F_{i}^{(2)}(t)=\int_{0}^{+\infty} \int_{0}^{+\infty} g_{i}\left(\tau_{1}, \tau_{2}\right) \zeta\left(t-\tau_{1}\right) \zeta\left(t-\tau_{2}\right) d \tau_{1} d \tau_{2}
$$

In this paper, wet surface model of the operating conditions platform is created by the finite element software Ansys, and then import the model into the Aqwa to calculate the second mean drift force for its second-order transfer function from 0 to 180 degree of three horizontal direction component (vertical swing, sway, yawing). Finally, the spectral analysis method is used to obtain the mean secondorder drift forces of platform. The results of second-order mean drift forces are shown as Fig. 4.

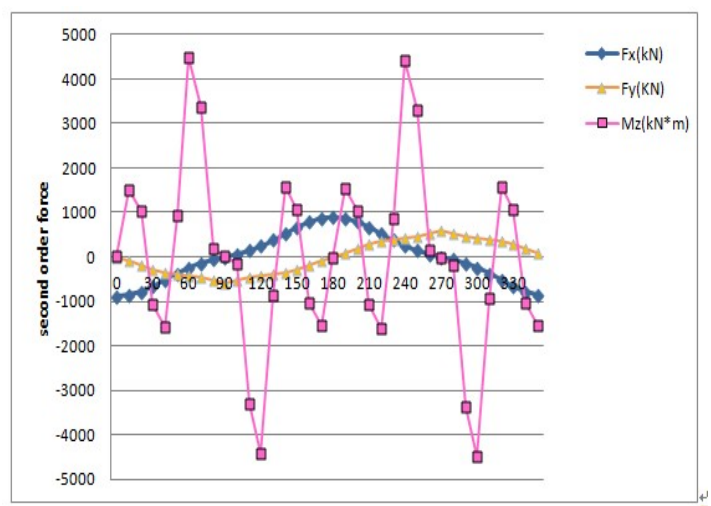

Figure 4. Second order force

\section{SimUlation}

\section{A. Linear Low-frequency Motion Model}

As in [7], in the usually case, with the origin of the body coordinate system does not necessarily coincide with the center of gravity of the platform, taking into account the symmetry of the platform, assuming the platform center of gravity is located in the point $\mathrm{C}\left(x_{c}, 0,0\right)$ with the body coordinate system, the quality of the platform is $\mathrm{m}$, the horizontal motions of the semisubmersible to the external forces acting on it:

$$
\left\{\begin{array}{l}
m\left(\dot{u}-v r-x_{C} r^{2}\right)=X_{\Sigma} \\
m\left(\dot{v}+u r+x_{C} \dot{r}\right)=Y_{\Sigma} \\
I_{Z} \dot{r}+m x_{C}(\dot{v}+u r)=N_{\Sigma}
\end{array}\right.
$$

Where $\mathrm{u}, \mathrm{v}$ and $\mathrm{w}$ means the linear velocity, $I_{Z}$ is the moment of inertia of the platform on the Z-axis The right end of the formula indicates that the sum of the level of external as well as around the $\mathrm{Z}$ axis of the sum of the outer torque.

In the process of dynamic positioning, the controller reads the position measuring system to get the position signal, its value and a predetermined target, then the controller computes the offset position deviation and the thrust needed by the external disturbance force, issues a directive on the thruster to produce thrust to make the boat as close as possible to the target location. Dynamic positioning is a specific application of automatic control, so you can use the method of classical control theory and modern control theory to design the controller. The most commonly and mature used system is now the second-generation dynamic positioning using PID controller and Kalman Filter.

\section{B. Kalman Filter}

The calculated vessel motions in the simulation program are a combination of low (LF) and high frequency (HF) motions. The low frequency motions originate from wave drift forces, current and wind loads, the high frequency motions from the first order wave forces. Due to the response time of the thrusters the DP system cannot compensate for the HF motions. Through the new measured data and the previous state value of the moment, combined with the system equation of state, in accordance with a specific recurrence formula, the Kalman filter can get the new state estimates value.

\section{PID Controller}

The estimated position of the vessel by the Kalman Filter is a low frequency signal that is used as input signal for the controller of the DP system. In order to improve the control performance of the control system, it normally takes to join the wind feed forward control system. The form of the whole control system is location information after the feedback system coupled with the wind feed-forward system. The introduction of wind feed forward PID (proportional - integral derivative) control rules can be expressed as:

$$
f(\varepsilon)=K_{P} \varepsilon+K_{I} \int \varepsilon d t+K_{D} \frac{d \varepsilon}{d t}+F_{W}\left(\alpha_{W}, v_{W}\right)
$$




\section{Dynamic Simulation}

In the first step, the measured current value of the state of motion is filtered by Kalman filtering, and the optimal estimate value of the motion of semi-platform is achieved. Next, compared with the set target value the state deviation can be known with position and heading angle deviation are imputed to the PID controller timely. The thrust instruction sent to the thrust allocation will be processed and each propeller to provide thrust. Finally, the effective thrust together with the environmental loads is imposed on the platform model. Doing the Loop until finished, the whole dynamic simulation platform movement and the thrust within the time history is done.

Environmental conditions: wind, waves and currents are in the same direction of 45 degree. The requirement of the simulation is shown as Table III.

TABLE III. DYNAMIC SIMULATION PARAMETER

\begin{tabular}{|c|c|c|c|}
\hline Item & Setting Value & Item & Setting Value \\
\hline Control mode & $\begin{array}{c}\text { PID+Kalman } \\
\text { filter }\end{array}$ & $\begin{array}{c}\text { The initial } \\
\text { coordinates }\end{array}$ & $\begin{array}{c}\mathrm{X}=0, \mathrm{Y}=0, \\
\Psi=0 \mathrm{deg}\end{array}$ \\
\hline $\begin{array}{c}\text { Thrust allocation } \\
\text { principles }\end{array}$ & Lower power & Initial velocity & $\begin{array}{c}\mathrm{Vx}=0, \mathrm{Vy}=0 \\
\mathrm{~V} \psi \Psi=0 \mathrm{deg}\end{array}$ \\
\hline Control point & $\begin{array}{c}\text { center of } \\
\text { gravity }\end{array}$ & $\begin{array}{c}\text { Positioning } \\
\text { target }\end{array}$ & $\begin{array}{c}\mathrm{X}=0, \mathrm{Y}=0, \\
\Psi=0 \mathrm{deg}\end{array}$ \\
\hline Simulation time & $2000 \mathrm{~s}$ & $\begin{array}{c}\text { Positioning } \\
\text { accuracy }\end{array}$ & $\begin{array}{c}\Delta \mathrm{X}=0, \Delta \mathrm{Y}=0, \\
\Delta \Psi=0 \mathrm{deg}\end{array}$ \\
\hline
\end{tabular}

The following is concluded from the results of simulation in full mode of operational condition presented in Fig 5 and Fig 6:

a) Platform can be maintained in operational condition full mode of positioning, with the positioning accuracy to meet the requirements.

b) The power of the thruster is mostly on the level of 30$40 \%$ of the low power. The higher efficiency of the propeller means lower fuel consumption and makes the dynamic positioning system of the economy improved.

c) In actual operation, controlling the bow to make the environment more favorable can reduce the power consumption.
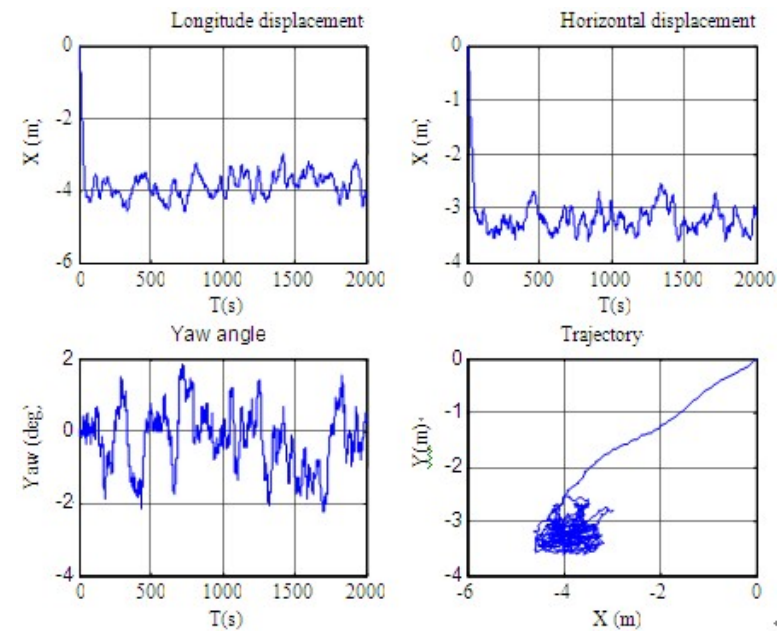

Figure 5. Horizontal movement of time trace and trajectory for the platform
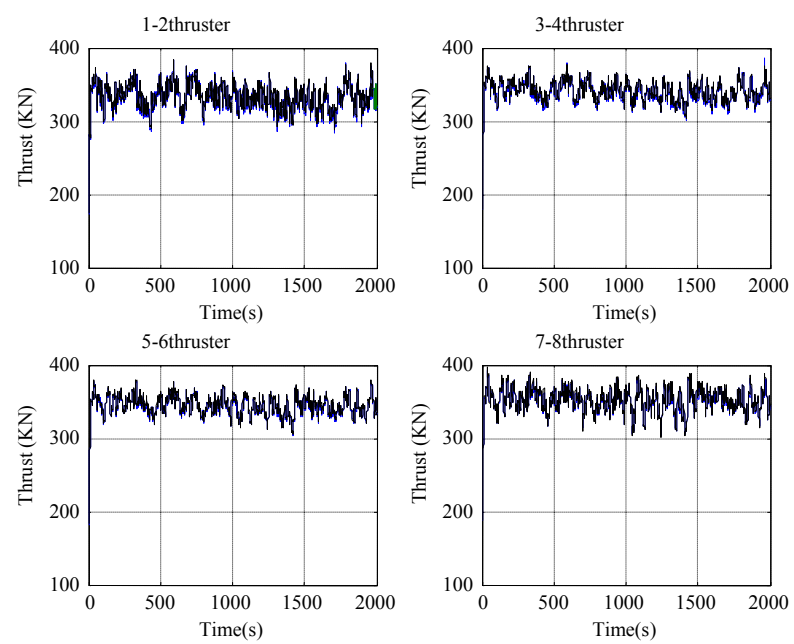

Figure 6. Time-history curve for the thrust of the thruster

\section{CONCLUSION}

A dynamic simulation is presented to perform DP of deepwater semi-submersible drilling platform equipped with 8 azimuthing thrusters. Mathematic model of low-frequency movement and environment load is created before the simulation. Simulation results show that:

The DP with PID controller and Kalman filter can fulfill the requirement and proves that the design is feasible. The power of the thruster can keep in acceptable range

The modular approach to the semi-submersible platform of the model for is practical. But to obtain accurate wind load, current load. The wind tunnel model test is needed. Only the operational condition and full mode is simulated. To do the further research, the failure mode is also needed to simulate.

\section{ACKNOWLEDGMENT}

The author would like to thank Wang Fang for her invaluable guidance and approval of the use of data from their model test programs.

\section{REFERENCES}

[1] MJ Morgan, "Dynamic Positioning of Offshore Vessels,"pp. 195-210, 1984.

[2] ZHAO Zhigao, YANG Jianmin, WANG Lei. "The development and research method of dynamic positioning system,'The Ocean Engineering, 2002, 20(1), pp.91-97.

[3] A.Lough. Dynamic Positioning. Lioyd's Register Technical Association. 1985

[4] van Walree Ir F. " Wind and Current Loads on Semisubmersibles ,'MARIN: No.49817-5-SE, 1991

[5] van Walree Ir F, Willemsen. “ Wind loads on offshore structures ,'Boss88 Conference, Trondheim, 1988

[6] Dalzell, J.F. "Application of the Functional Polynomial Model to the Ship Added Resistance Problem,"11The Symposium on Naval Hydrodynamics , London, 1976

[7] Li Dianpu, "Ship motion modeling" Harbin Engineering University Press, Harbin 1999,pp. 1-90 